\title{
Bumetanide-related effect on attention to face parts in children and adolescents with autism spectrum disorder using the eye tracking algorithm
}

\author{
Ahmad Delrobaee', Mehdi Tehrani-Doost ${ }^{2,3 *}$ iD, Mohammadtaghi Joghataei ${ }^{4}$, Katayoon Razjouyan $^{5}$, \\ Anahita Khorrami Benaraki ${ }^{6}$, Raheleh Mollajani ${ }^{7}$
}

\author{
1. $\mathrm{MD}, \mathrm{PhD}$ Candidate in Cognitive Neuroscience, Institute for Cognitive Science Studies, Tehran, Iran \\ 2. Professor of Child and Adolescent Psychiatry and Cognitive Neuroscience, Research Center for Cognitive and Behavioral Sciences, Tehran Univer- \\ sity of Medical Sciences, Tehran, Iran \\ 3. Professor of Child and Adolescent Psychiatry and Cognitive Neuroscience, Institute for Cognitive Science Studies, Tehran Iran \\ 4. Professor of Neuroanatomy and Neuroscience, Faculty of Advanced Technologies in Medicine, Cellular and Molecular Research Center, Iran Uni- \\ versity of Medical Sciences, Tehran, Iran \\ 5. Associate Professor of Child and Adolescent Psychiatry, Shahid Beheshti University of Medical Sciences, Department of Psychiatry, Imam Hossein \\ Hospital, Tehran, Iran \\ 6. $\mathrm{MD}, \mathrm{PhD}$ in Cognitive Neurosciences, Brain \& Cognition Clinic, Tehran, Iran \\ 7. PhD Student of Cognitive Neuroscience, Institute for Cognitive Science Studies, Tehran, Iran
}

Recieved: 14 Feb. 2018

Revised: 22 May 2019

Accepted: 11 Jun. 2019

Keywords

Bumetanide

Autism spectrum disorder

Eye contact

Eye tracking

Face

Corresponding author

Mehdi Tehrani-Doost, Professor of Child and Adolescent Psychiatry and Cognitive Neuroscience, Research Center for Cognitive and Behavioral Sciences, Tehran University of Medical Sciences, Roozbeh Hospital, Tehran, Iran

Email: Tehranid@sina.tums.ac.ir

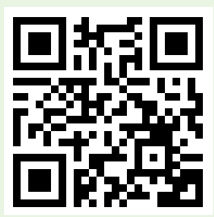

\section{Abstract}

Introduction: Autism Spectrum Disorder (ASD) is a neurodevelopmental disorder characterized by impairment in social communication and repetitive and stereotyped behaviors. It has been shown that a diuretic drug named bumetanide had a considerable influence on improving social communication in these patients. One of the important features in making social communication is eye contact; this research aimed to evaluate the efficacy of this medication on improving pattern of eye contact and the other parts of the face in children and adolescents with ASD.

Methods: This single group clinical trial research is conducted on 20 children and adolescents aged from 7 to 15 years old with high function Autism Spectrum Disorder. After discontinuing the previously taking medications, Childhood Autism Rating Scale (CARS), Kiddie- Schedule for Affective and Schizophrenia (KSADS), Wechsler Intelligence Scale for Social Responsiveness Scale (SRS), and Children-Revised Form (WISC-R) were administered to each participant. A dose of $1 \mathrm{mg}$ Bumetanide $(0.5 \mathrm{mg}$ in the morning and $0.5 \mathrm{mg}$ in the evening) during 90 Days was given to the participants. Eye tracking evaluation administered while the participants were looking at the pictures of faces before and after the intervention. The number and duration of fixation to each area in each image as the variables recorded.

Results: A comparison of pre and post-intervention showed no significant differences in terms of the eye tracking variables.

Conclusion: Using Bumetanide did not have any significant effect on the amount of looking at the eyes in children and adolescents with ASD, despite improved symptoms and severity of autism and some behavioral problems. 
D)

\section{بررسى تاثير داروى بومتانايد بر ميزان توجه به اجزاى جهره در كودكان و نوجوانان با اختلال طيف اوتيسم با استفاده از سيستم ردياب جشمى}

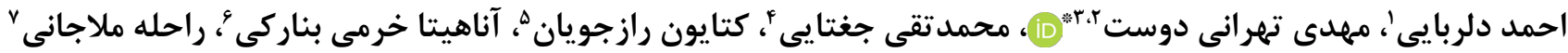

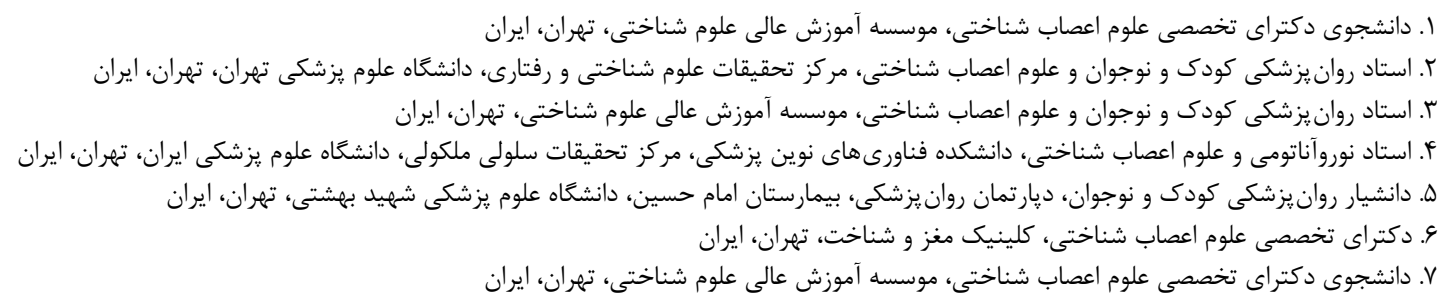

\section{ars}

مقدمه: اختلال طيف اوتيسم، يك اختلال عصبى رشدى است كه با نقص در ارتباطات اجتماعى و الكوهاى رفتارى كليشهاى مشخص مىشود. نشان داده شده است كه دارويى ديورتيك به نام بومتانايد، تاثير قابل توجهى را در بهبود ارتباط اجتماعى در اين بيماران داشته است. نظر به اينكه يكى از شاخصهاى مهم در برقرارى روابط اجتماعى، تماس جشمى مى باشد، هدف از انجام اين مطالعه بررسى تاثير اين دارو بر تصحيح الكوى نحاه به جشم و ديكر اجزاى صورت در كودكان و نوجوانان مبتلا به اختلال اوتيسم بود. روش كار: مطالعه حاضر يك كارآزمايى بالينى تك كروهى به صورت يك سو كور بود. شركت كنندًان شامل •r كودى V Vا ها سال مبتلا به اختلال طيف اوتيسهم با عملكرد بالا بود. بعد از قطع داروهاى قبلى آزمون هاى مقياس درجهبندى اوتيسم دوران كودكى (CARS)، مصاحبه تشخيصى نيمه ساختاريافته (KSADS)، معيار پاسخدهى اجتماعى (SRS)، مقياس تجديدنظر شده هوشى براى كودكان (WISC-R) براى هر شركت كننده انجام شد. مداخله دارويى روزى يك ميلى گرم قرص بومتانايد به صورت نيم ميلى نكاه شركت كنندكان به تصاوير جهره قبل و بعد از مداخله انجام شد. متغيرهاى تعداد و زمان نكاه به هر منطقه در هر تصوير ثبت كرديد. يافته ها: مقايسه قبل و بعد از مداخله تعداد نعاه به جشم براى هر بيمار براى هر تصوير و زمان نكاه به جشم براى هر بيمار براى هر تصوير تفاوت معنادارى را نشان نداد (ه•/P>). نتيجه گَيرى: مصرف داروى بومتانايد بر روى ميزان نحاه به جشم در كودكان اوتيستيك اثر معنادارى نداشته گَرجه علايم و شدت اوتيسم و برخى مشكلات رفتارى را بهبود داده است.

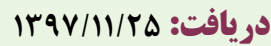

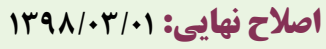

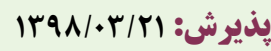

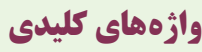
بومتانايد اختلال طيف اوتيسم ارتباط جشمى اختلاط طيف

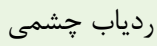
جهره

نويسنله مسئول مهدى تهرانى دوست، استاد روانيزشكى مدئول كودى و نوجوان و علوم اعصاب شناختى، مركز تحقيقات علوم شناختى و رفتارى، دانشعاه علوم يزشكى تهران، بيمارستان روزبه، تهران، ايران

ايميل: Tehranid@sina.tums.ac.ir

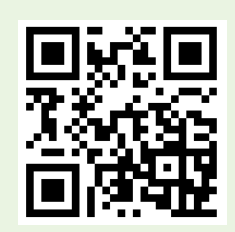

dol doi.org/10.30699/icss.21.4.84

\section{مقلدمه}

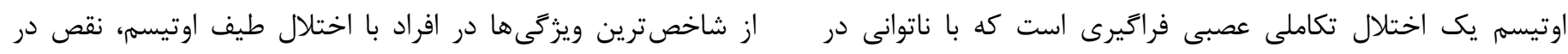

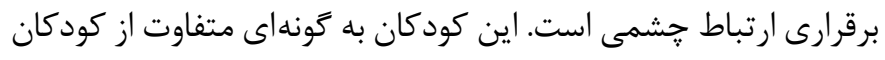

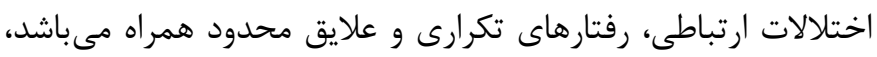

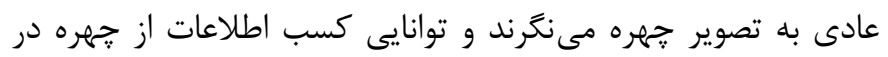

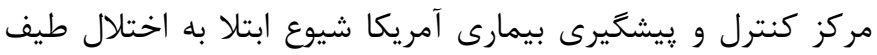

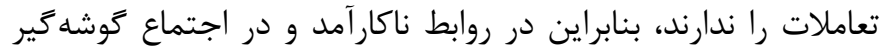
اوتيسم را يك در هر ه9 كودى (1) و سازمان بهداشت جهانى ابتلا

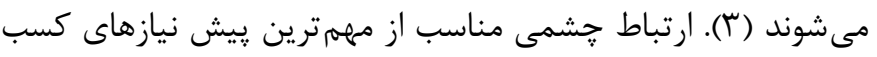

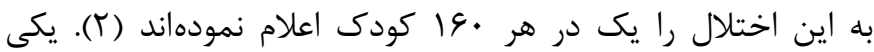


سلولى موجب تقويت عملكرد مهارى كابا و ايجاد تعادل تحريكىـ مهارى آن مى كردد (•r). مطالعات نشان دادند كه مصرف بومتانايد به

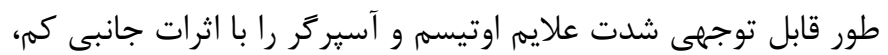

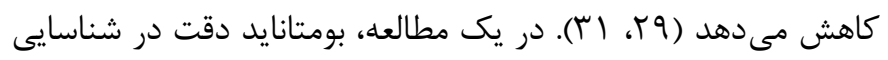

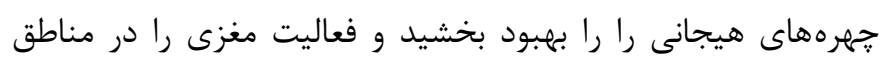

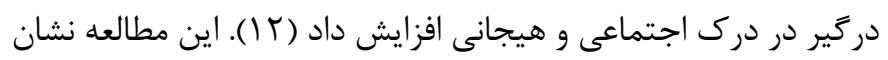

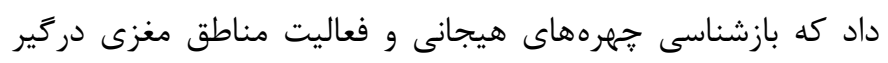

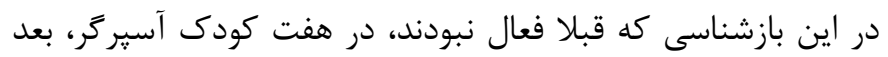

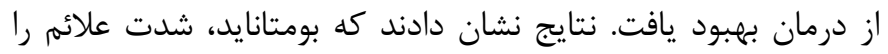

كاهش داده و تعامل آنها را با محيط افزايش مى دهد (r) (I).

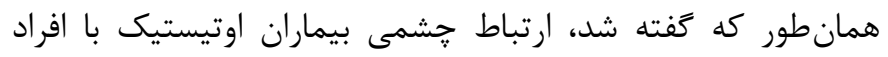
معمولى متفاوت است و بيشتر به لب و دهان افراد به جاى جشمه، نتاه

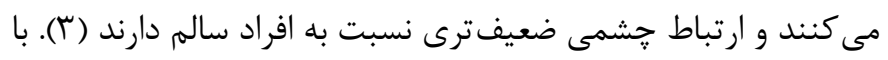

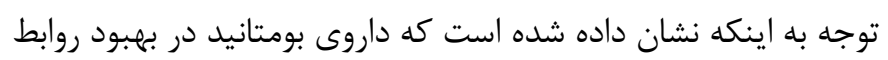

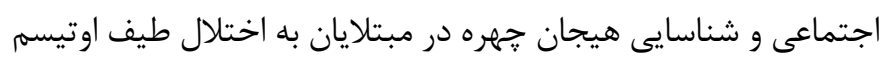

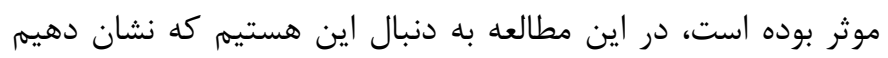

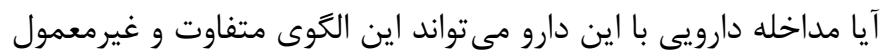

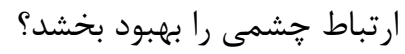

\section{روش كار}

مطالعه حاضر يك كارآزمايى بالينى تك گروهى به صورت يك سو كور

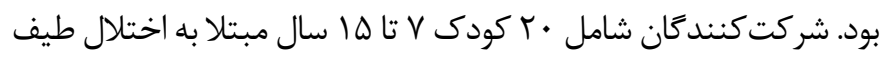

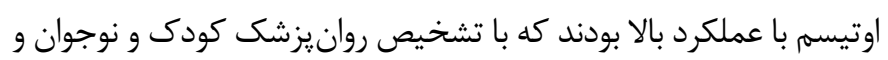

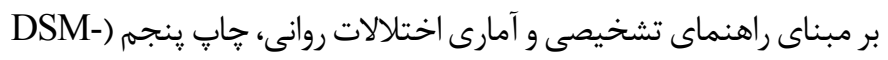

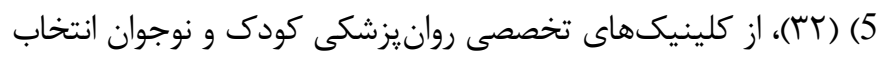
شدند. در اين مطالعه از آزمونهاى مقياس درجهابندى اوتيسم دوران كودكى (CARS)، مصاحبه تشخيصى نيمه ساختاريافته (KSADS)، معيار קاسخدهى اجتماعى (SRS)، مقياس تجديدنظر شده هوشى براى

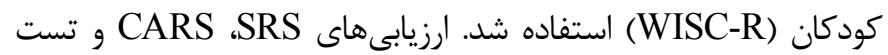

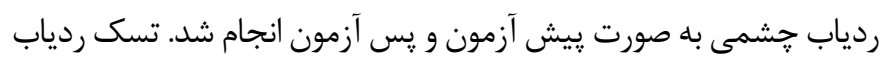

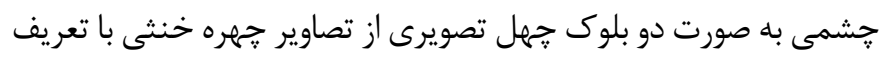
مناطق جشم و لب و فضاى اطراف ارائه كرديد.

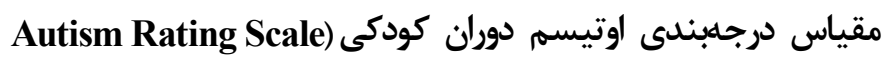
Childhood مورد كاركردهاى مختلف افراد اوتيستيك مى باشد كه متغيرهاى مختلف رفتارى نظير برقرارى ارتباط با مردم، تقليد، ارتباطات غير كلامى، مقدار فعاليت و غيره را مورد سنجش قرار مى دهد (بr).
مهارتهاى اجتماعى است. همجنين در مطالعات مختلف نشان داده شده است كه افراد مبتلا به طيف اوتيسم در يردازش اطلاعات اجتماعى

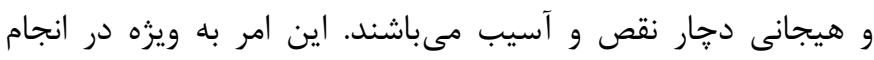

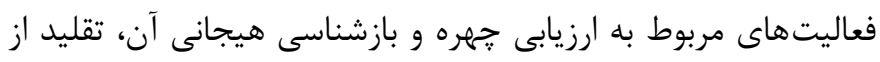

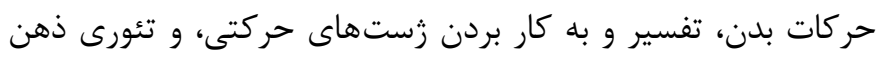

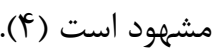
در حال حاضر هيج درمان دارويى قطعى براى كاهش علايم اختلال

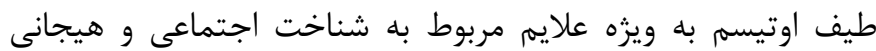
وجود ندارد (ه). در سطح سلولى و مولكولى در اختلال طيف اوتيسم يِيامرسانى سيستم كابارزيك تحت تاثير قرار مى گيرد و منجر به عدم تعادل بين تحريك و مهار نورونى مىشود (4-9). در افراد مبتلا به اين اختلال، سيخنالينَ كابا كه توسط نورونهاى كابارزيك توليد مىشوند و در عملكردهاى شناختى سطح بالا كاربردى مى باشندا،

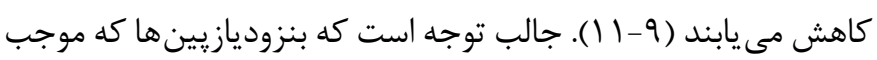

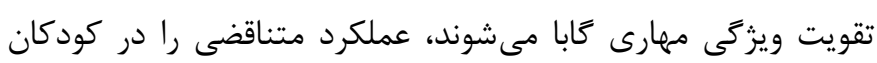
مبتلا به اوتيسم نشان داده و موجب افزايش تحريك و ساير علائم مى-شوند (r ا, با). نشان داده شده است كه اين واكنش متناقض، از

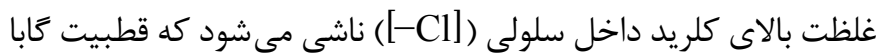

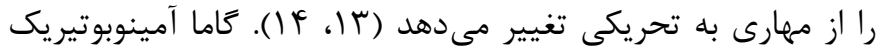

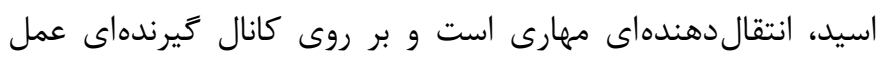

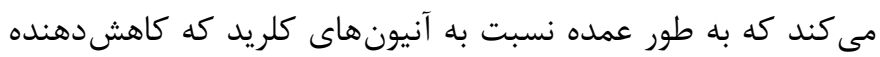

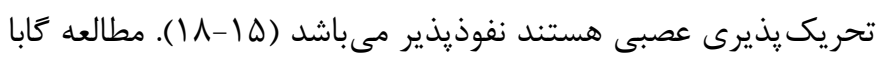

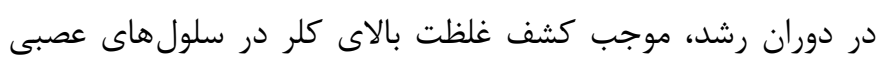

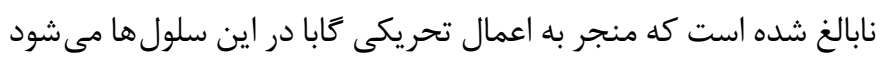
(9). كاهش تدريجى غلظت كلر نشان مى دهد كه تغيير ديلاريزه به هاييريلاريزه كه مرتبط با جابجايى تحريك با مهار مىباشد در طول تكامل محفوظ مانده است و راه حلى را براى مشكل عمده رشد فراهم

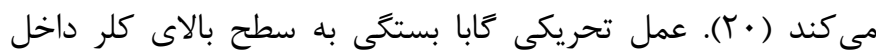

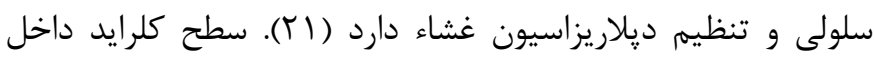

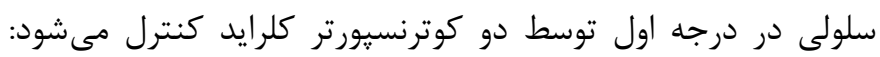
واردكننده كلر NKCC1 و خارجكننده كلر SCC2

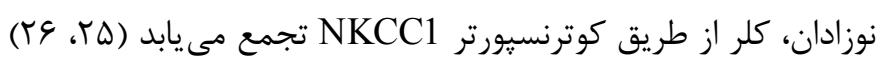

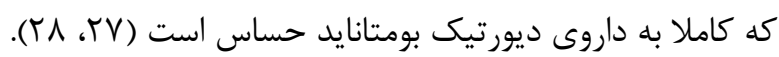
بومتانايد يك داروى ديورتيك است، كه در درمان فشار خون بالا، ديسيلازى برونكوينومونى و سندرم نفروتيك استفاده مى شود؛ اين دارو دئان يك آنتاكونيست خاص NKCC1 با كرايش بالا مىباشد كه موجب درون كاهش غلظت كلر داخل سلولى مىشود (9 (Y). كاهش غلظت كلر درون 
مدت ... ميلى ثانيه صفحه كاملا خاكسترى با يك علامت بعلاوه (+) سفيد در وسط آن، تصاوير جهرهها را از هم جدا مى كند. محدوده نغاه هر فرد به هر تصوير به سه منطقه مورد نظر (AOI) به نامهاى جشم، لب و فضا تقسيم شد. طبق تصوير شماره ا منطقه جشم توسط يك

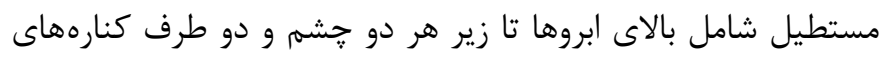
جشم انتخاب شد. منطقه لب توسط يكى مستطيل از بالاى بينى تا زير لب و تا كنارههاى لب محدود شد. منطقه فضا هم تمام منطقه تصوير بغير از دو منطقه جشم و لب را شامل مى شد.

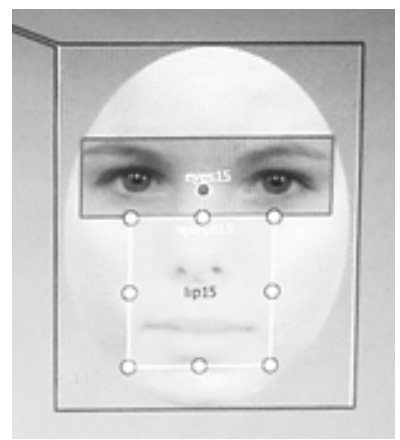

تصوير ا. مناطق مورد نظر (AOI) شامل سه منطقه جشم، لب و فضا

در اين مدت دستگاه به ثبت دقيق اين موارد در هر تصوير مىيردازد: تعداد نتاه به هر منطقه، زمان نغاه به هر منطقه، تعداد و زمان كل نحاهها در هر تصوير. با استفاده از اطلاعات ثبت شده از آزمايشات و لهان سيستم ردياب جشمى، متغيرهاى زير هركدام دوبار (ييش و پس از مداخله) محاسبه و آماده تحليل كرديد:

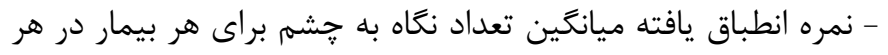
تصوير (نسبت تعداد نغاه به جشم در كل تصاوير به تعداد كل نغاهها)

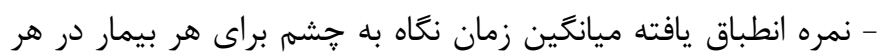
تصوير (نسبت زمان نعاه به جشم در كل تصاوير به كل زمان ارائه تصويرها) - نمره انطباق يافته ميانگين تعداد نغاه به لب براى هر بيمار در هر

تصوير (نسبت تعداد نكاه به لب در كل تصاوير به تعداد كل نكاه ها)

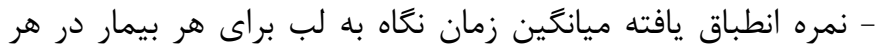
تصوير (نسبت زمان نكاه به لب در كل تصاوير به كل زمان ارائه تصويرها) - عدد خام تعداد نكاه به خشم براى هر تصوير براى هر فرد (مجموع

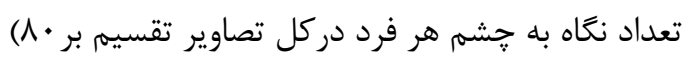
- عدد خام تعداد نكاه به لب براى هر تصوير براى هر فرد (مجموع تعداد نغاه به لب هر فرد در كل تصاوير تقسيم بر •(A) - عدد خام زمان نكاه به جشم براى هر تصوير براى هر فرد (مجموع زمان نكاه به جشم هر فرد در كل تصاوير تقسيم بر •^) - عدد خام زمان نغاه به لب براى هر تصوير براى هر فرد (مجموع زمان

\section{and Schizophrenia) مصاحبه تشخيصى نيمه ساختاريافته} Kiddiè-Schedule for Affective ساختاريافته كه براى ارزيابى دورههاى فعلى و قبلى علائم و اختلالات روان يزشكى كودكان و نوجوانان به صورت مصاحبه با والدين، كودك و در نهايت به دست آوردن خلاصهاى از نمره كذارىها مىباشد ( (ب). نسخه

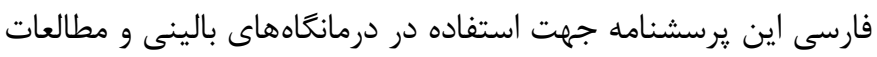
تحقيقاتى توسط شهريور و همكاران اعتباريابى شده است (ها؟). مقياس تجديدنظر شده هوشى وكسلر براى كودكان (WISC-R): اين تُونيط مقياس داراى rا خرده آزمون مى باشد كه ب آزمون آن جنبه ذخيره دارد. 4 آزمون كلامى و 4 آزمون غير كلامى (عملى) است. اين آزمون موقعيت نسبى شخص را در مقايسه با همسالانش به دست مى دهد و

يك برآورد كلى از توانيى هاى ذهنى او در اختيار مى كذارد (4)). معيار ياسخدهى اجتماعى (Social Responsiveness Scale):

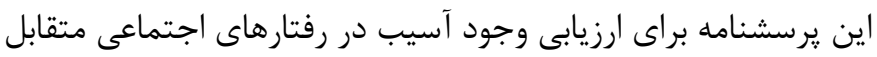

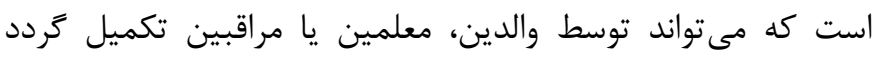

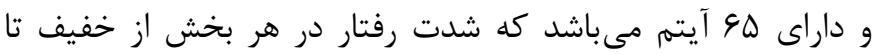

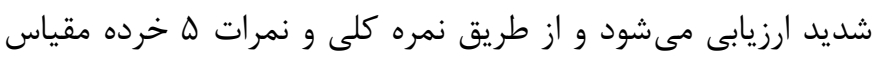
محاسبه مى گردد (YV). نسخه فارسى اين يرسشنامه جهت استفاده در درمانگاههاى بالينى و مطالعات تحقيقاتى توسط تهرانى دوست و

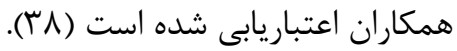
سيستم ردياب جشمى (Eye Track): در اين يزوهش جهت رديابى حركات קشم، از دستكاه ردياب جشمى شصت هرتز شركت

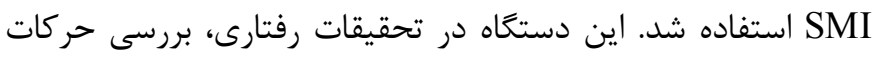

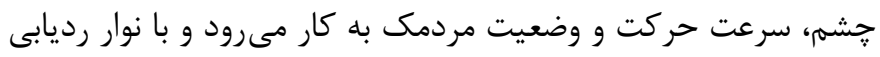

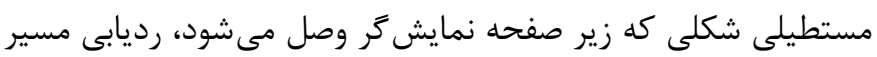
حركت مردمك جشمها را انجام مى دهد. تسك سيستم رديابى جشمى: براى انجام آزمايش، دو بلوى تصويرى شامل مجموعا •r تصوير سياه و سفيد از جهره ده نفر (ينج زن و ينج مرد) با حالت كاملا خنثى كه از مجموعه تصاوير رَدبود (Bad Boud انتخاب شدهاند، تهيه شد. به علت طولانى شدن تست و عدم تحمل كودى اوتيستيك جهت نشستن يشت دستكاه و تمركز بر انجام

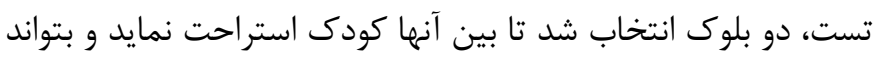

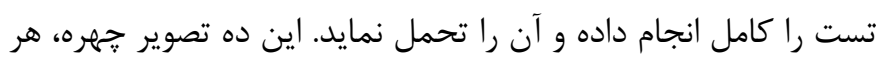

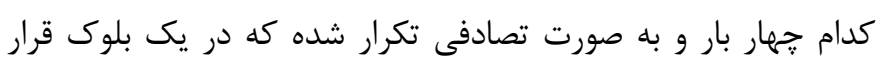
داده شدهاند. آزمايش با نشان دادن دو بلوك جهل تصويرى يكسان كه تهات بين هر بلوك دو دقيقه استراحت داده مىشد، انجام گرفت. هر كدام از

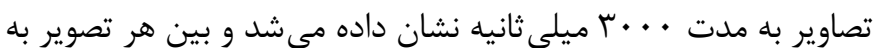


IR.IUMS.REC.1395.4537 و مدت اعتبار سه سال از كميته اخلاق معاونت تحقيقات و فناورى دانشگاه علوم يزشكى و خدمات بهداشتى

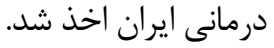

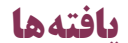

شركت كنندًان در اين مطالعه شامل • † نفر كودك و نوجوان مبتلا به

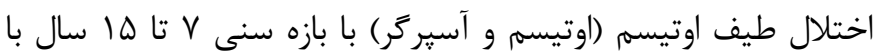

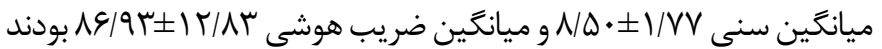
كه در حين دوره مصرف دارو، ه نفر آنان به دلايل عدم همكارى والدين، عدم تحمل عوارض دارو و نيز بىقرارى به علت قطع كردن داروهاى ديكر،

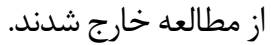
نمره كل آزمون CARS بعد از مداخله به طور معنادارى كاهش يافت

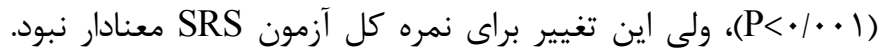

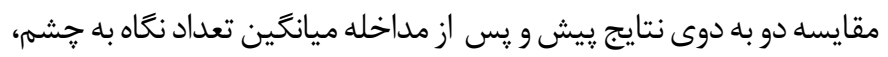

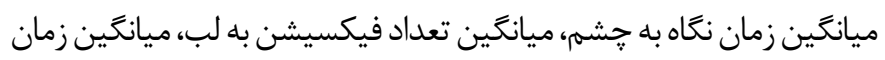
نغاه به لب، عدد خام تعداد نگاه به جشم، عدد خام تعداد نكاه به لب، عدد خام زمان نگاه به جشم، عدد خام زمان نحاه به لب و ميانگَين تعداد كل نكاهها به تصاوير با استفاده از آزمون تى زوجى (Paired t-test) انجام شد. همجنين مقايسه دو به دوى يیش آزمون تعداد نكاه به جشم با پِيش آزمون تعداد نحاه به لب، مقايسه يֶ آزمون اين دو، مقايسه پِيش آزمون زمان نحاه به קشم با پيش آزمون زمان نكاه به لب، مقايسه پِس آزمون اين دو نيز انجام شد. نتايج در جدول ا و Y نشان داده شده است.

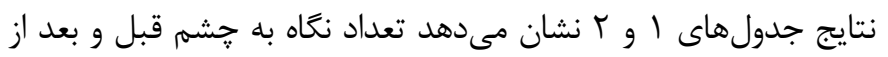
مصرف دارو اختلاف معنادارى ندارد اكر خه از نظر عددى بهبود داشته است

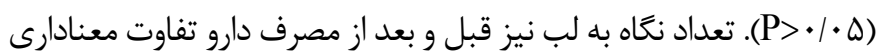

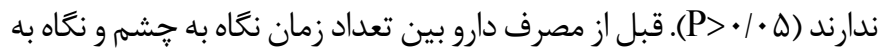
لب اختلاف معنادار است ولى نكاه به جشم بيشتر از نغاه به لب بوده است

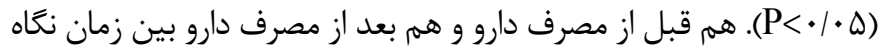
به جشم و نكاه به لب اختلاف معنادار وجود دارد ولى اين اختلاف به اين

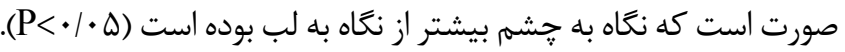

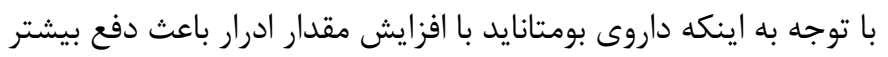

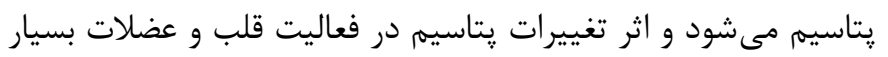

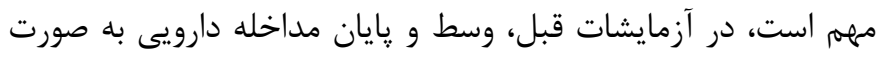

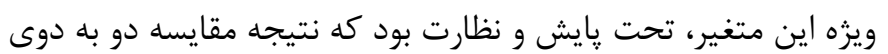
آن قبل و بعد از مصرف دارو در جدول ب كزارش شده است. مقايسه مقدار يتاسيم سرم خون قبل و بعد از مصرف دارو در آزمون تى زوجى، تفاوت معنادارى را نشان نداد (ه •/P>).
نعاه به لب هر فرد در كل تصاوير تقسيم بر •^) - ميانخين تعداد كل نغاه براى هر تصوير براى هر فرد (مجموع كل تعداد نكاه ها به همه تصاوير تقسيم بر •(^)

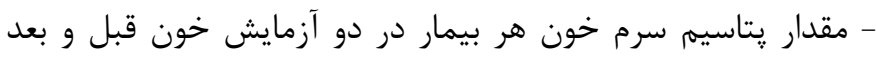

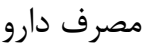
مداخله دارويى: نمونها به مدت سه مارو، روزى دوبار ه/ • ميلى گرم

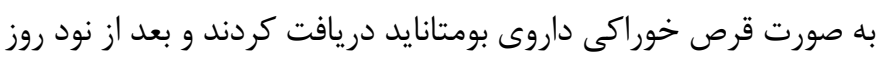
دارو قطع شد. جهت بِيخيرى وضعيت بيمار و كنترل مشكلات احتمالى مصرف دارو، افراد شركت كننده در طول دوره مصرف دارو تحت بررسى و ارزيابى هاى فشارخون وضعيتى، آلرزى، كَرفتخى عضلات، ضعف و سستى، اسهال، درد عضلانى، درد مفاصل، سرگيجه و تهوع و استفراغ قرار مى كرفتند. همجنين براى هر بيمار قبل و وسط و انتهاى مصرف آنافي

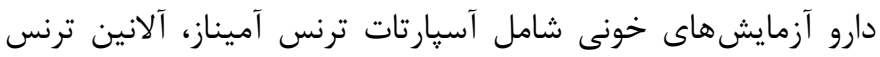

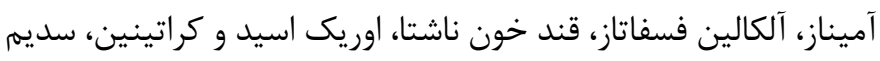

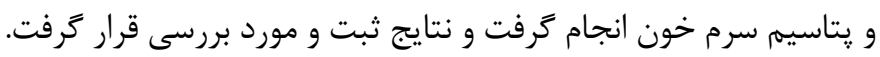
فرايند اجرا: ابتدا بيماران توسط يك فوق تخصص روانين يزشكى كودى و نوجوان مورد ارزيابى تشخيصى قرار گرفتند. افرادى كه داراى معيارهاى ورود بودند يس از تكميل فرم رضايتنامه ورود به طرح توسط والدين آنها، وارد مطالعه شدند. سيس درمانهاى دارويى ديكر آنان به جز ملاتونين براى اختلالات خواب، با دستور روانيزشك متخصص

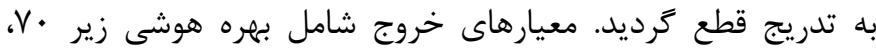
ناهنجارى هاى كروموزومى واضح، يا سوابق نورولوزيكى از جمله صرع و تشنج تبدار، سابقه آلرزى به سولفوناميدها، اختلال كبد، اختلال كليه،

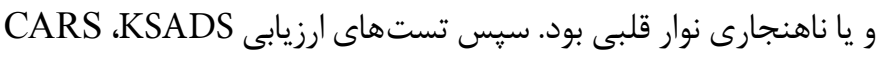

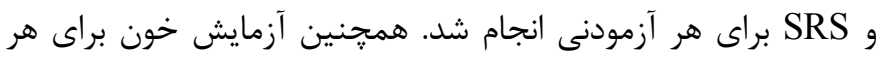

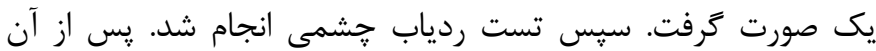
مصرف دارو شروع گرديد. شركت كنند به صورت تماس تلفنى و هر ماه حضورى تحت بررسى و كنترل وضعيت و

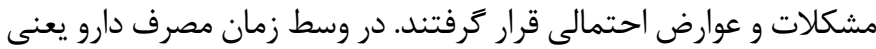
جهل و ينج روز بعد از شروع دارو، تستهاى CARS و SRS و آزمايش خون كرفته شد و توسط روان يزشك كودى و نوجوان مورد ارزيابى قرار

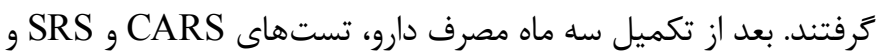

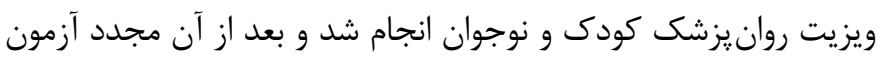
ردياب جشمى انجام كرديد. تحليل آمارى: دادها با آزمون تى زوجى و آزمون همبستخى ييرسون به وسيله نرمافزار SPSS-23 مورد تجزيه و تحليل قرار كرفت. كواهى تاييد اخلاقى اين طرح تحقيقاتى با كد اخلاق به شماره 
جدول ا. نتايج آزمون مقايسه t دو به دوى متغيرهاى ردياب جشمى در تستهاى پِيش آزمون و يس آزمون

\begin{tabular}{|c|c|c|c|c|c|}
\hline $\mathbf{P}$ & $\mathbf{T}$ & انحر اف معيار & ميانگين & مر حله & مقايسه دو به دوى متغيرها \\
\hline \multirow{2}{*}{$\cdot \mid \Delta \omega$} & \multirow{2}{*}{ - $-|9| r$} & .119 & $\cdot / 4$ & پِيش از مداخله & \multirow{2}{*}{ 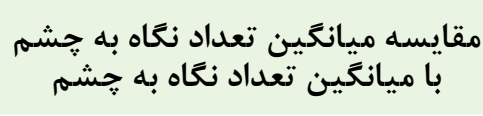 } \\
\hline & &.$/ 1 T$ & . KT & پֶ از مداخله & \\
\hline \multirow{2}{*}{. $\mid 491$} & \multirow{2}{*}{$-\cdot / V F V$} & $\cdot 1 \cdot 9$ & Tr & ي ريش از مداخله & \multirow{2}{*}{ مقايسه ميانَينينين تعداد نعاد نَاه به لبه لب } \\
\hline & & $\cdot / 14$ & $\cdot / r \Delta$ & 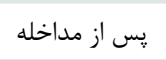 & \\
\hline \multirow{2}{*}{$\cdot \mid 4 \cdot 1$} & \multirow{2}{*}{$-\cdot$ |^⿻9 } & $\cdot / 10$ & $\cdot / \pi \Delta$ & ي ريش از مداخله & \multirow{2}{*}{ 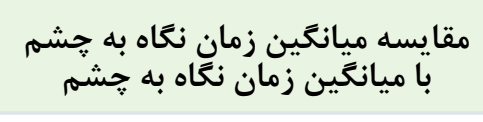 } \\
\hline & & $\cdot / 14$ & . & 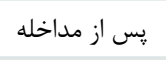 & \\
\hline \multirow{2}{*}{.1990} & \multirow{2}{*}{ - epet } & $\cdot / 11$ & $\cdot \pi$ & 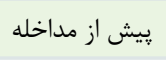 & \multirow{2}{*}{ 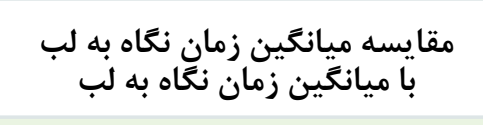 } \\
\hline & & $\cdot / 14$ & $\cdot|r|$ & 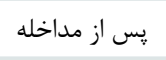 & \\
\hline \multirow{2}{*}{$\cdot / 4 \cdot 1$} & \multirow{2}{*}{$-\cdot$ | $₫ 99$} & $f \Delta s / \cdot V$ & $1 \cdot 9 \cdot 1 / 9$ & ي قِيش از مداخله & \multirow{2}{*}{ 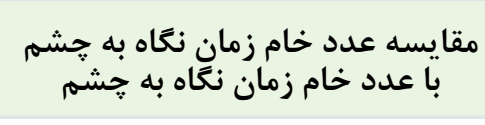 } \\
\hline & & $r \Lambda T / 19$ & $119 \cdot / r \Lambda$ & يس از مداخله & \\
\hline \multirow{2}{*}{.1990} & \multirow{2}{*}{$-\cdot$ RFt } & TrQ/TF & $\Delta 99|\Delta|$ & 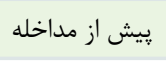 & \multirow{2}{*}{ مقايسه عدد خام زمان نعاه زماه به لب لب } \\
\hline & & rVq/If & GTE|GT & 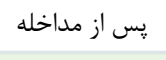 & \\
\hline \multirow{2}{*}{$\cdot \mid 9 \cdot r$} & \multirow{2}{*}{ r } & $\cdot / \mathrm{A}$ & $1 / \Lambda r$ & ي ريش از مداخله & \multirow{2}{*}{ 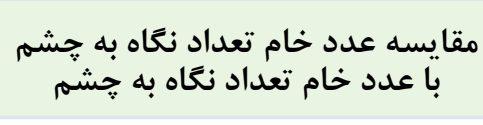 } \\
\hline & & $\cdot 19$ & $1 / v a$ & 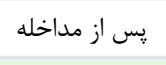 & \\
\hline \multirow{2}{*}{$.19 \vee 9$} & \multirow{2}{*}{.$- / .41$} & $\cdot 109$ & $1 / \cdot \Delta$ & رِيش از مداخله & \multirow{2}{*}{ مقايسه عدد خام تعداد نعاد نغاه بـ به لب لب } \\
\hline & & $\cdot 190$ & $1 / \cdot 0$ & 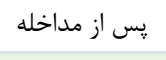 & \\
\hline \multirow{2}{*}{.$/ 1 F V$} & \multirow{2}{*}{ I/ATD } &.$/ 91$ & $F / \& V$ & ي بيش از مداخله & \multirow{2}{*}{ مقايسه عدد خام تعداد كل نعَاه هاه } \\
\hline & & $\cdot / A F$ & $r / r$. & يس إز مداخله & \\
\hline
\end{tabular}

جدول r. نتايج مقايسه ميزان نخاه به جشم و لب قبل از مداخله با هم و بعد از مداخله با هم

\begin{tabular}{|c|c|c|c|c|c|}
\hline $\mathbf{P}$ & $\mathbf{T}$ & انحراف معيار & ميانگين & مر حله & مقايسه دو به دوى متغيرها \\
\hline \multirow{2}{*}{$.1 . .9$} & \multirow{2}{*}{$r / T \Delta}$. &.$/ 19$ & $\cdot / 4$ & بيش از مداخله & \multirow{2}{*}{ 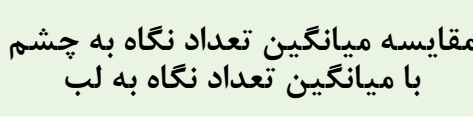 } \\
\hline & & $\cdot 1 \cdot 9$ & 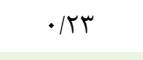 & بيش از مداخله & \\
\hline \multirow{2}{*}{.1 .94} & \multirow{2}{*}{ r/r. } &.$/ 14$ & . KT & 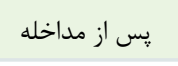 & \multirow{2}{*}{ 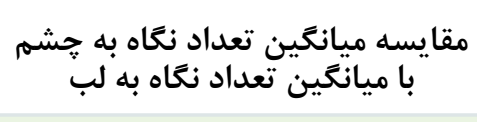 } \\
\hline & & $\cdot / 14$ & $\cdot / r \Delta$ & 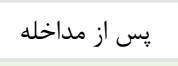 & \\
\hline \multirow{2}{*}{$.1 \cdot 10$} & \multirow{2}{*}{ r/VAl } & $\cdot / 10$ & $\cdot \pi \omega$ & بيش از مداخله & \multirow{2}{*}{ 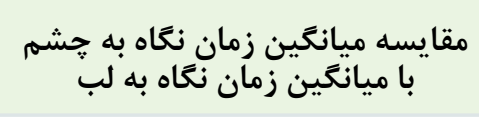 } \\
\hline & & $\cdot / 11$ & $\cdot \pi$ & ي بيش از مداخله & \\
\hline \multirow{2}{*}{$.1 \cdot 10$} & \multirow{2}{*}{ T/VA) } & $\varphi \Delta s / \cdot V$ & $1 \cdot 9 \cdot 1 / 79$ & 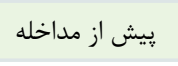 & \multirow{2}{*}{ 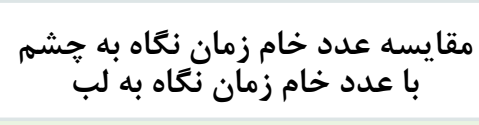 } \\
\hline & & rTQ/TY & $\Delta 9 \&|\Delta|$ & ي بيش از مداخله & \\
\hline \multirow{2}{*}{$\cdot 1 \cdot \cdot v$} & \multirow{2}{*}{ 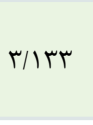 } & $\cdot / 1 r$ & $\cdot / 49$ & 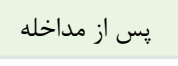 & \multirow{2}{*}{ 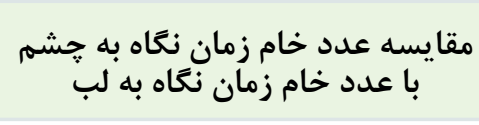 } \\
\hline & & $\cdot / 14$ & $\cdot|r|$ & 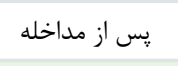 & \\
\hline \multirow{2}{*}{$\cdot \cdot v$} & \multirow{2}{*}{ 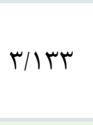 } & $r \Lambda r / / q$ & $119 \cdot / r \Lambda$ & 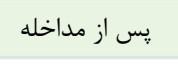 & \multirow{2}{*}{ 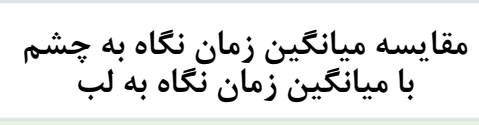 } \\
\hline & & $r \vee q / 1 F$ & GTE|GT & 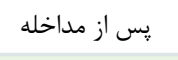 & \\
\hline \multirow{2}{*}{$\cdot / \cdot 1$} & \multirow{2}{*}{$r / 9 V r$} & $\cdot \mid \wedge \Lambda$ & I/Ar & بيش از مداخله & \multirow{2}{*}{ 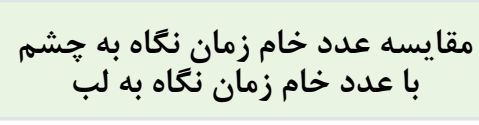 } \\
\hline & & $\cdot \mid \Delta Q$ & $1 / \cdot \Delta$ & 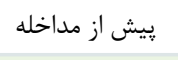 & \\
\hline \multirow{2}{*}{$.1 \cdot 10$} & \multirow{2}{*}{ r/VVr } & $\cdot 19$ & $1 / V \Delta$ & 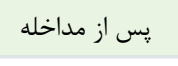 & \multirow{2}{*}{ 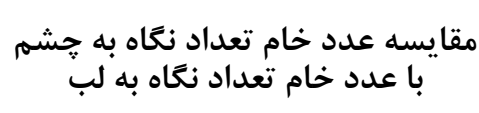 } \\
\hline & & .190 & $1 / \cdot 0$ & يّ از مداخله & \\
\hline
\end{tabular}




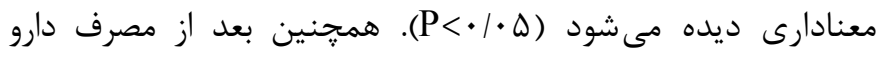

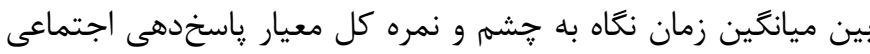

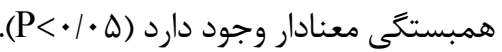
همجِنين آزمون همبستكى بِيرسون بين نتايج نمره هوشى تست كلامى

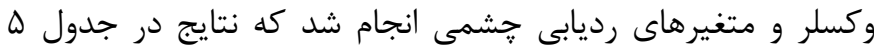
نشان داده شده است. همانطور كه در اين جدول ديده مىشود هيج همبستكى معنادارى در يِش آزمون و يس آزمون، بين نمره هوش كلامى با متغيرهاى ردياب جشمى وجود نداشته است (ه •/P> (P).

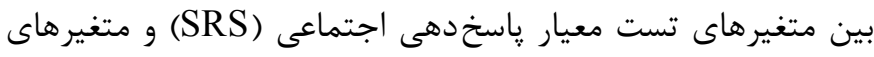
ردياب جشمى دو بار (قبل و بعد مصرف دارو) آزمون همبستكى لئى ييرسون انجام كرفت كه نتايج در جدول أ نشان داده شده است. نتايج جدول \& رابطهاى را قبل از مصرف دارو بين متغيرهاى رِاسخدهى اجتماعى و متغيرهاى رديابى جشمى نشان نداد (ه •/P>)، ولى بعد از مصرف دارو بين ميانگين تعداد نگاه به جشم و نمره كل معيار

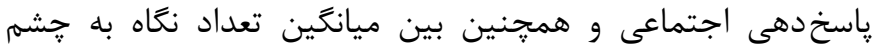

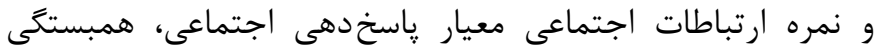

جدول س. نتايج آزمون مقايسه t دو به دوى مقدار پتاسيم سرم خون قبل و بعد از مصرف دارو

\begin{tabular}{|c|c|c|c|c|c|}
\hline $\mathbf{P}$ & $\mathbf{T}$ & انحراف معيار & ميانگين & مرحله & مقايسه دو به دوى متغير ها \\
\hline \multirow{2}{*}{$\cdot / r q}$. & \multirow{2}{*}{$1 / 1 \cdot r$} & $\cdot / \pi 9$ & $p / r q$ & بيش از مداخله & \multirow[b]{2}{*}{ يتاسيم سرم خون } \\
\hline & & . $/ \Delta r$ & $F / T \Delta$ & يس از مداخله & \\
\hline
\end{tabular}

جدول f. نتايج ضريب همبستكى rr بين متغيرهاى تست معيار קاسخدهى اجتماعى و متغيرهاى ردياب خشمى

\begin{tabular}{|c|c|c|c|c|}
\hline ارتباطات اجتماعى إز مداخله & ارتباطات اجتماعى بيش از مداخله & ن & 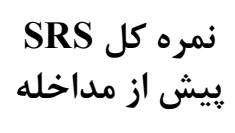 & \\
\hline$-\cdot / \Delta \mu r^{*}$ & (Ir) & $-\cdot \mid 9 r \cdot *$ & - - Rtt & تعداد نعاه به جֶشم \\
\hline .1111 & $-\cdot / K F F$ & . & $-\cdot / 1 \cdot 9$ & تعداد نغاه به لب \\
\hline$-\cdot / r V q$ & $-\cdot / \cdot \Lambda \mu$ & $-\cdot \mid \Delta Q Y^{*}$ & $-\cdot / r V \Lambda$ & زمان نكاه به جشهم \\
\hline$\cdot / \cdot V G$ & $-\cdot / F \varphi$ & $.11 \cdot 9$ & $-\cdot / l V V$ & زمان نغاه به لب \\
\hline
\end{tabular}

$* \mathrm{P}<\cdot / \cdot \Delta$

\begin{tabular}{|c|c|c|}
\hline هوش كلامى از مداخله & هيش از مداخلى كلامى & \\
\hline$\cdot / T \Lambda$. & $\cdot / \cdot V^{c}$ & تعداد نگاه به جشم \\
\hline$\cdot|| \Delta \mid$ &.$/ 1 F$. & تعداد نكاه به لب \\
\hline$\cdot / \% \wedge q$ & $\cdot / T V \Delta$ & زمان نكَاه به جشم \\
\hline$\cdot / 4 \& 9$ & .1191 & زمان نكًاه به لب \\
\hline
\end{tabular}

$* \mathrm{P}<\cdot / \cdot \Delta$

و توجه به صورت را در بيماران مبتلا به اوتيسم بهبود دهد. به طور كلى نتايج اين مطالعه نشان داد كه نگاه به جشم در شركت كنندگان مبتلا به اوتيسم مورد مطالعه، قبل و بعد مصرف دارو تفاوت معنادارى ندارند.
اين مطالعه به اين منظور انجام شد كه تاثير داروى بومتانايد بر ميزان توجه به اجزاى صورت و نگاه و توجه به جشم در كودكان مبتلا به اوتيسم معلوم شود و اينكه جقدر اين دارو مى تواند مشكل نكاه به جشم 
اجتماعى همبستكى و ارتباط منفى ديده شد. با توجه به اينكه در اين

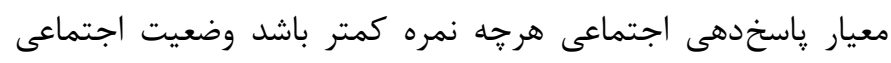

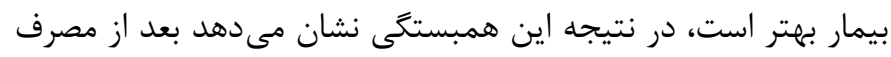

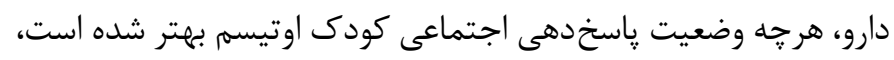

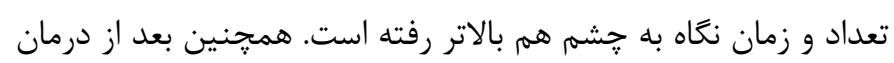

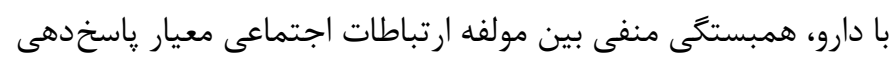

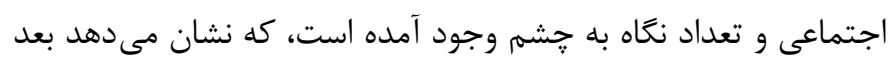
از مصرف دارو هرجه ارتباطات اجتماعى بيمار بهتر شده، تعداد نعاه به جشم در بيمار نيز بهتر و بالاتر رفته است.

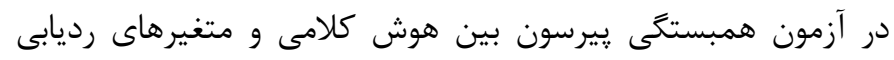

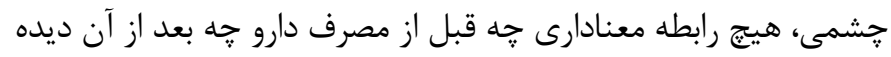

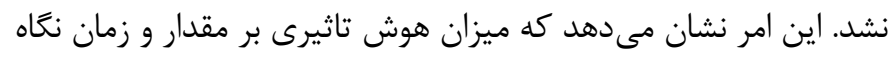

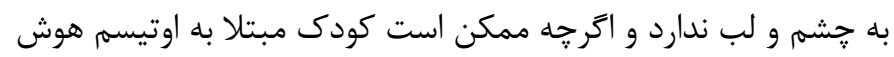

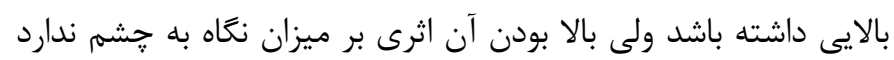

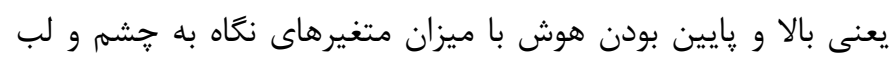

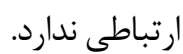
محدوديتهاى اين مطالعه كه مىتوان به آن اشاره كرد اين است كه،

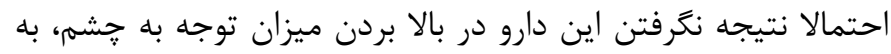
علت كم بودن تعداد نمونهها بوده است. همجنين ممكن است ميزان

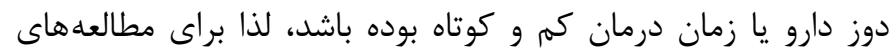

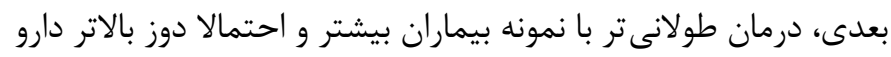

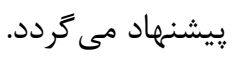

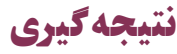

نتايج مطالعه حاضر نشان داد كه مصرف داروى بوتانيد كه بر روى سيستم كابارزيك تاثير دارد و مى تواند باعث بهبود علائم اصلى اختلال

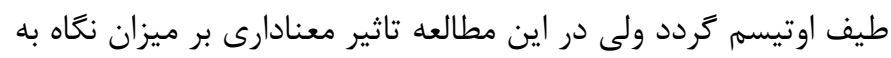
جشم در اين بيماران حاصل نشد اگرجه باعث توجه بيشترى به جشم

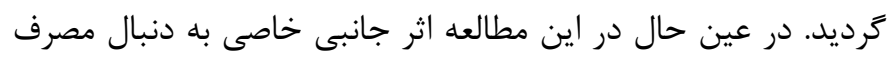
اين دارو نشان داده نشد.

\section{تشكر و قدرداذى - ت دانى}

در يايان از ستاد توسعه علوم شناختى كه اين طرح تحقيقاتى را مورد

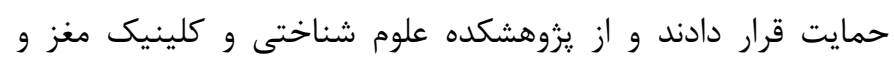
شناخت و از خانم محمدزاده، خانم تاينده و خانم مهدوى كه در اجراى طرح همكارى داشتهاند، تشكر و قدردانى مى شود.
در مورد لب هم ميزان نكاه قبل و بعد مصرف دارو اختلاف معنادارى

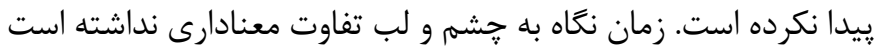

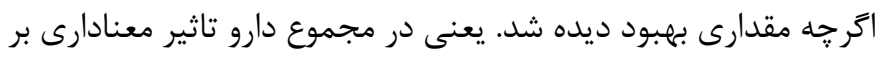

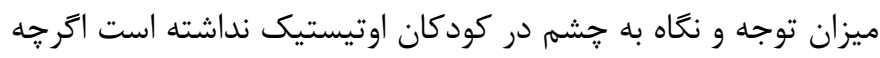
از نظر عددى بهبود داشته است. قبل از مصرف دارو بين تعداد و زمان

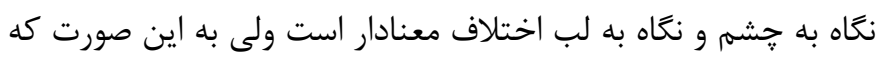

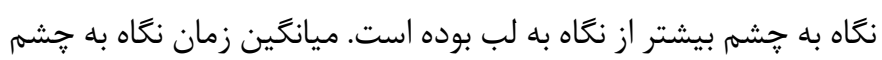

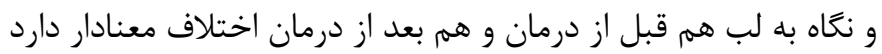

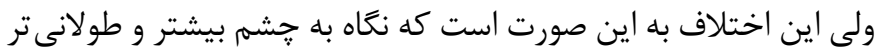

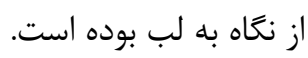

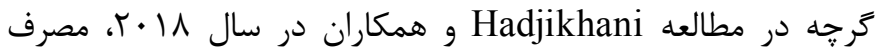

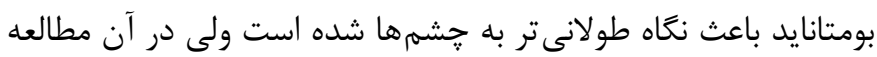
مصرف بومتانايد به جاى سه ماه، ده ماه بوده است و شركت كنندكان

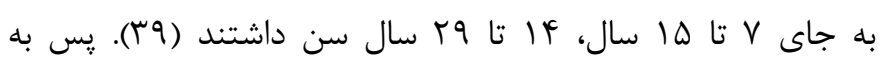

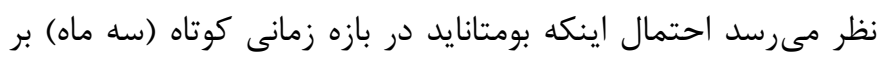
بهبود شدت اختلال اوتيسم و در موارد استفاده طولانى تر (ده ماه) بر اختلالات ارتباطى مانند توجه به جشم اثركذار باشد، وجود دارد.

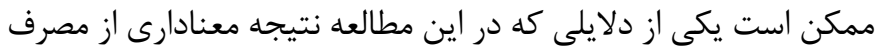

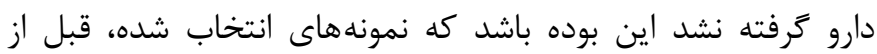

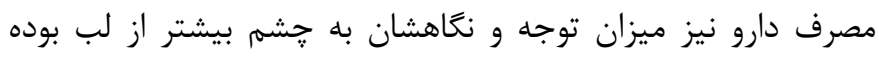

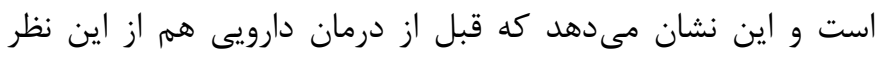

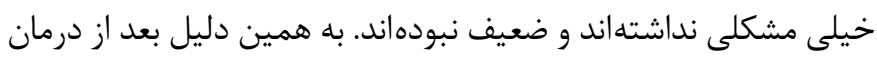
دارويى علىرغم اينكه تغيير و بهعبودى داشتهاند ولى اين تغيير معنادار

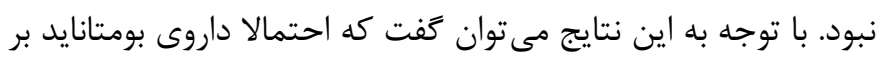

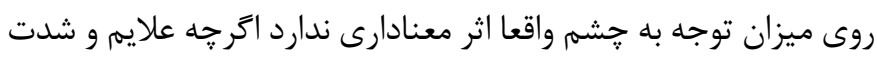

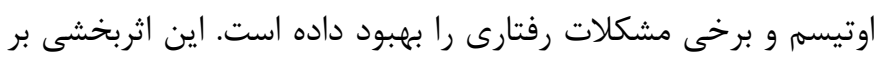

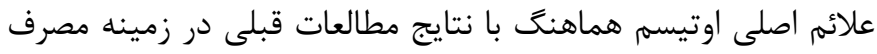

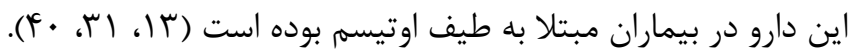

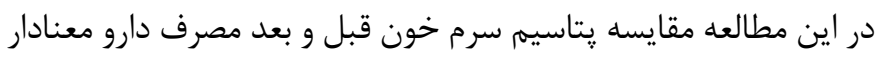
نبود، كه نشان مى دهد مصرف دارو مشكل خاصى در ميزان يتاسيم خون

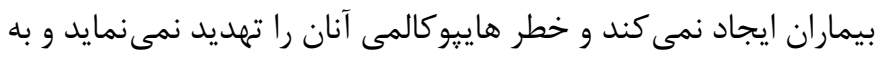

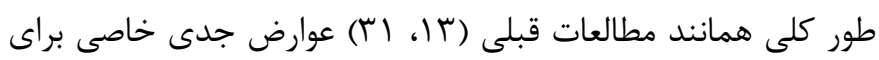

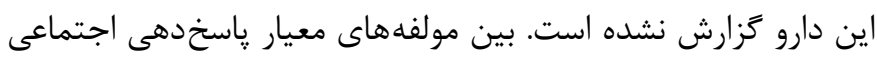
SRS رابطهاى وجود نداشت ولى بعد از مصرف دارو رابطهها تصحيح شد.

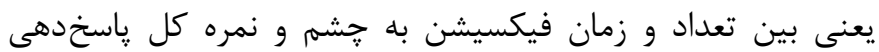




\section{References}

1. Data \& Statistics on Autism Spectrum Disorder. Centers for Disease Control and Prevention Web site. https://www.cdc. gov/ncbddd/autism/data.html. Updated November 15, 2018. Accessed February 11, 2019.

2. Autism Spectrum Disorders. World Health Organization Web site. https://www.who.int/news-room/fact-sheets/detail/ autism-spectrum-disorders. Updated April 4, 2017. Accessed February 11, 2019.

3. Pelphrey KA, Sasson NJ, Reznick JS, Paul G, Goldman BD, Piven J. Visual scanning of faces in autism. Journal of Autism and Developmental Disorders. 2002;32(4):249-261.

4. Baron-Cohen SE, Tager-Flusberg HE, Cohen DJ. Understanding other minds: Perspectives from autism. New York:Oxford University Press;1994.

5. Patin A, Hurlemann R. Social cognition. In: Kantak K., Wettstein J, editors. Cognitive enhancement. Handbook of experimental pharmacology. Vol 228. Berlin:Springer, Cham;2015. pp. 271-303.

6. Chao HT, Chen H, Samaco RC, Xue M, Chahrour M, Yoo J, et al. Dysfunction in GABA signalling mediates autism-like stereotypies and Rett syndrome phenotypes. Nature. 2010;468(7321):263-269.

7. Dossche D. GABA in autism and related disorders. San Diego:Elsevier Academic Press. 2005.

8. Gogolla N, LeBlanc JJ, Quast KB, Südhof TC, Fagiolini M, Hensch TK. Common circuit defect of excitatory-inhibitory balance in mouse models of autism. Journal of Neurodevelopmental Disorders. 2009;1(2):172-181.

9. Pizzarelli R, Cherubini E. Alterations of GABAergic signaling in autism spectrum disorders. Neural Plasticity. 2011;2011. 10. Brown C, Gruber T, Boucher J, Rippon G, Brock J. Gamma abnormalities during perception of illusory figures in autism. Cortex. 2005;41(3):364-376.

11. Lewis DA, Hashimoto T, Volk DW. Cortical inhibitory neurons and schizophrenia. Nature Reviews Neuroscience. $2005 ; 6(4): 312-324$.
12. Hadjikhani N, Zürcher NR, Rogier O, Ruest T, Hippolyte L, Ben-Ari Y, et al. Improving emotional face perception in autism with diuretic bumetanide: A proof-of-concept behavioral and functional brain imaging pilot study. Autism. 2015;19(2):149-157.

13. Marrosu F, Marrosu G, Rachel MG, Biggio G. Paradoxical reactions elicited by diazepam in children with classic autism. Functional Neurology. 1987;2(3):355-361.

14. Nardou R, Yamamoto S, Chazal G, Bhar A, Ferrand N, Dulac O, et al. Neuronal chloride accumulation and excitatory GABA underlie aggravation of neonatal epileptiform activities by phenobarbital. Brain. 2011;134(4):987-1002.

15. Andersen P, Eccles JC, Lyning Y. Pathway of postsynaptic inhibition in the hippocampus. Journal of Neurophysiology. 1964;27(4):608-619.

16. Eccles JC. The development of the cerebellum of vertebrates in relation to the control of movement. Naturwissenschaften. 1969;56(11):525-534.

17. Ito M. The molecular organization of cerebellar long-term depression. Nature Reviews Neuroscience. 2002;3(11):896-902.

18. Roberts E. Failure of GABAergic inhibition: A key to local and global seizures. Advances in Neurology. 1986;44:319-341. 19. Ben-Ari Y, Holmes GL. The multiple facets of $\gamma$-aminobutyric acid dysfunction in epilepsy. Current Opinion in Neurology. 2005;18(2):141-145.

20. Ben-Ari Y, Gaiarsa JL, Tyzio R, Khazipov R. GABA: A pioneer transmitter that excites immature neurons and generates primitive oscillations. Physiological Reviews. 2007;87(4):1215-1284.

21. Staley K, Smith R, Schaack J, Wilcox C, Jentsch TJ. Alteration of GABAA receptor function following gene transfer of the CLC-2 chloride channel. Neuron. 1996;17(3):543-551. 22. Cohen I, Navarro V, Clemenceau S, Baulac M, Miles R. On the origin of interictal activity in human temporal lobe epilepsy in vitro. Science. 2002;298(5597):1418-1421.

23. Rivera C, Voipio J, Payne JA, Ruusuvuori E, Lahtinen $\mathrm{H}$, Lamsa $\mathrm{K}$, et al. The $\mathrm{Kp} / \mathrm{Clcotransporter} \mathrm{KCC} 2$ renders 
GABA hyperpolarizing during neuronal maturation. Nature. 1999;397(6716):251-255.

24. Delpire E. Cation-chloride cotransporters in neuronal communication. Physiology. 2000;15(6):309-312.

25. Payne JA, Rivera C, Voipio J, Kaila K. Cation-chloride co-transporters in neuronal communication, development and trauma. Trends in Neurosciences. 2003;26(4):199-206.

26. Yamada J, Okabe A, Toyoda H, Kilb W, Luhmann HJ, Fukuda A. $\mathrm{Cl}-$ uptake promoting depolarizing GABA actions in immature rat neocortical neurones is mediated by NKCC1. The Journal of Physiology. 2004;557(3):829-841.

27. Hannaert P, Alvarez-Guerra M, Pirot D, Nazaret C, Garay R. Rat NKCC2/NKCC1 cotransporter selectivity for loop diuretic drugs. Naunyn-Schmiedeberg's Archives of Pharmacology. 2002;365(3):193-199.

28. Isenring P, Jacoby SC, Payne JA, Forbush B. Comparison of $\mathrm{Na}-\mathrm{K}-\mathrm{Cl}$ cotransporters. NKCC1, NKCC2, and the HEK cell Na-L-Cl cotransporter. The Journal of Biological Chemistry. 1998;273(18):11295-11301.

29. Lemonnier É, Degrez C, Phelep M, Tyzio R, Josse F, Grandgeorge $\mathrm{M}$, et al. A randomised controlled trial of bumetanide in the treatment of autism in children. Translational Psychiatry. 2012;2(12):e202.

30. Dzhala VI, Talos DM, Sdrulla DA, Brumback AC, Mathews GC, Benke TA, et al. NKCC1 transporter facilitates seizures in the developing brain. Nature Medicine. 2005;11(11):1205-1213. 31. Lemonnier E, Ben-Ari Y. The diuretic bumetanide decreases autistic behaviour in five infants treated during 3 months with no side effects. Acta Paediatrica. 2010;99(12):1885-1888. 32. American Psychiatric Association. Diagnostic and Statistical Manual of Mental Disorders 5th Edition:DSM-5®. Arlington, VA:American Psychiatric Pub;2013.

33. Schopler E, Reichler RJ, DeVellis RF, Daly K. Toward ob- jective classification of childhood autism: Childhood Autism Rating Scale (CARS). Journal of Autism and Developmental Disorders. 1980;10(1):91-103.

34. Kaufman J, Birmaher B, Brent D, Rao UM, Flynn C, Moreci P, Williamson D, Ryan N. Schedule for affective disorders and schizophrenia for school-age children-present and lifetime version (K-SADS-PL): Initial reliability and validity data. Journal of the American Academy of Child \& Adolescent Psychiatry. 1997;36(7):980-988.

35. Shahrivar Z, Kousha M, Moallemi S, Tehrani-Doost M, Alaghband-Rad J. The reliability and validity of kiddie-schedule for affective disorders and schizophrenia-present and life-time version-Persian version. Child and Adolescent Mental Health. 2010;15(2):97-102.

36. Wechsler D. Wechsler Intelligence Scale for Children. Wechsler Intelligence Scale for Children. San Antonio, TX:Psychological Corporation;1949.

37. Pine E, Luby J, Abbacchi A, Constantino JN. Quantitative assessment of autistic symptomatology in preschoolers. $A u$ tism. 2006;10(4):344-352.

38. Tehrani-Doost M, Shahrivar Z, Torabi N, Ansari S, Haji-Esmaeelzadeh M, Saeed-Ahmadi S. Cross-cultural validation and normative data of the Social Responsiveness Scale in a group of Iranian general child population. Journal of Autism and Developmental Disorders. 2018:1-8.

39. Hadjikhani N, Johnels JÅ, Lassalle A, Zürcher NR, Hippolyte L, Gillberg C, et al. Bumetanide for autism: More eye contact, less amygdala activation. Scientific Reports. 2018;26;8(1):1-8.

40. Du L, Shan L, Wang B, Li H, Xu Z, Staal WG, Jia F. A pilot study on the combination of applied behavior analysis and bumetanide treatment for children with autism. Journal of Child and Adolescent Psychopharmacology. 2015;25(7):585-588. 